\title{
Comparative Study of Factor Xa Fluorogenic Substrates and Their Influence on the Quantification of LMWHs
}

\author{
Vanessa Castro-Lopez \\ CIC microGUNE \\ Leanne F. Harris \\ Technological University Dublin, leanne.harris@tudublin.ie \\ James S. O'Donnell \\ Trinity College Dublin
}

See next page for additional authors

Follow this and additional works at: https://arrow.tudublin.ie/scschbioart

Part of the Biology Commons

\section{Recommended Citation}

Castro-Lopez, V., Harris, L., O'Donnell, J. and Killard, A. (2011). Comparative study of Factor Xa fluorogenic substrates and their influence on the quantification of LMWHs. ,Analytical and Bioanalytical Chemistry, 2011 Jan;399(2):691-700. doi:10.1007/s00216-010-4314-3

This Article is brought to you for free and open access by the School of Biological Sciences at ARROW@TU Dublin. It has been accepted for inclusion in Articles by an authorized administrator of ARROW@TU Dublin. For more information, please contact arrow.admin@tudublin.ie, aisling.coyne@tudublin.ie,gerard.connolly@tudublin.ie. Funder: Enterprise Ireland

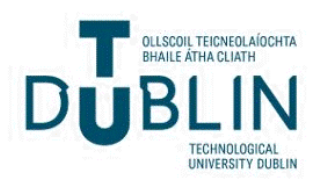




\section{Authors}

Vanessa Castro-Lopez, Leanne F. Harris, James S. O'Donnell, and Anthony J. Killard

This article is available at ARROW@TU Dublin: https://arrow.tudublin.ie/scschbioart/155 


\section{Dear Author}

Here are the proofs of your article.

- You can submit your corrections online, via e-mail or by fax.

- For online submission please insert your corrections in the online correction form. Always indicate the line number to which the correction refers.

- You can also insert your corrections in the proof PDF and email the annotated PDF.

- For fax submission, please ensure that your corrections are clearly legible. Use a fine black pen and write the correction in the margin, not too close to the edge of the page.

- Remember to note the journal title, article number, and your name when sending your response via e-mail or fax.

- Check the metadata sheet to make sure that the header information, especially author names and the corresponding affiliations are correctly shown.

- Check the questions that may have arisen during copy editing and insert your answers/corrections.

- Check that the text is complete and that all figures, tables and their legends are included. Also check the accuracy of special characters, equations, and electronic supplementary material if applicable. If necessary refer to the Edited manuscript.

- The publication of inaccurate data such as dosages and units can have serious consequences. Please take particular care that all such details are correct.

- Please do not make changes that involve only matters of style. We have generally introduced forms that follow the journal's style.

- Substantial changes in content, e.g., new results, corrected values, title and authorship are not allowed without the approval of the responsible editor. In such a case, please contact the Editorial Office and return his/her consent together with the proof.

- If we do not receive your corrections within 48 hours, we will send you a reminder.

- Your article will be published Online First approximately one week after receipt of your corrected proofs. This is the official first publication citable with the DOI. Further changes are, therefore, not possible.

- The printed version will follow in a forthcoming issue.

\section{Please note}

After online publication, subscribers (personal/institutional) to this journal will have access to the complete article via the DOI using the URL:

http://dx.doi.org/10.1007/s00216-010-4314-3

If you would like to know when your article has been published online, take advantage of our free alert service. For registration and further information, go to:

http://www.springerlink.com.

Due to the electronic nature of the procedure, the manuscript and the original figures will only be returned to you on special request. When you return your corrections, please inform us, if you would like to have these documents returned. 


\section{Metadata of the article that will be visualized in OnlineFirst}

\begin{tabular}{|c|c|c|c|}
\hline 1 & Article Title & \multicolumn{2}{|c|}{$\begin{array}{l}\text { Comparative study of Factor Xa fluorogenic substrates and their } \\
\text { influence on the quantification of LMWHs }\end{array}$} \\
\hline 2 & \multicolumn{3}{|l|}{ Article Sub- Title } \\
\hline 3 & $\begin{array}{l}\text { Article Copyright - } \\
\text { Year }\end{array}$ & \multicolumn{2}{|c|}{$\begin{array}{l}\text { Springer-Verlag } 2010 \\
\text { (This will be the copyright line in the final PDF) }\end{array}$} \\
\hline 4 & Journal Name & \multicolumn{2}{|c|}{ Analytical and Bioanalytical Chemistry } \\
\hline 5 & \multirow{8}{*}{$\begin{array}{l}\text { Corresponding } \\
\text { Author }\end{array}$} & Family Name & Killard \\
\hline 6 & & Particle & \\
\hline 7 & & Given Name & Anthony J. \\
\hline 8 & & Suffix & \\
\hline 9 & & Organization & Dublin City University \\
\hline 10 & & Division & $\begin{array}{l}\text { Biomedical Diagnostics Institute, National Centre for } \\
\text { Sensor Research }\end{array}$ \\
\hline 11 & & Address & Dublin 9 , Ireland \\
\hline 12 & & e-mail & tony.killard@dcu.ie \\
\hline 13 & \multirow{8}{*}{ Author } & Family Name & Castro-López \\
\hline 14 & & Particle & \\
\hline 15 & & Given Name & Vanessa \\
\hline 16 & & Suffix & \\
\hline 17 & & Organization & Dublin City University \\
\hline 18 & & Division & $\begin{array}{l}\text { Biomedical Diagnostics Institute, National Centre for } \\
\text { Sensor Research }\end{array}$ \\
\hline 19 & & Address & Dublin 9 , Ireland \\
\hline 20 & & e-mail & \\
\hline 21 & \multirow{8}{*}{ Author } & Family Name & Harris \\
\hline 22 & & Particle & \\
\hline 23 & & Given Name & Leanne F. \\
\hline 24 & & Suffix & \\
\hline 25 & & Organization & Dublin City University \\
\hline 26 & & Division & $\begin{array}{l}\text { Biomedical Diagnostics Institute, National Centre for } \\
\text { Sensor Research }\end{array}$ \\
\hline 27 & & Address & Dublin 9 , Ireland \\
\hline 28 & & e-mail & \\
\hline 29 & & Family Name & O’Donnell \\
\hline 30 & & Particle & \\
\hline 31 & & Given Name & James S. \\
\hline 32 & & Suffix & \\
\hline
\end{tabular}


33

34

35

36 Author

37

38

39

40

41 Schedule

42

43
Organization

Division

Address

Organization

Division

Address

e-mail
Dublin City University

Biomedical Diagnostics Institute, National Centre for Sensor Research

Dublin 9 , Ireland

National Centre for Hereditary Coagulation Disorders, St. James's Hospital

Haemostasis Research Group, Trinity College Dublin

Dublin 8 , Ireland

$\begin{array}{ll}\text { Received } & 18 \text { August } 2010 \\ \text { Revised } & 6 \text { October } 2010 \\ \text { Accepted } & 7 \text { October } 2010\end{array}$

Low molecular weight heparins (LMWHs) are recognised as the preferred anticoagulants in the prevention and treatment of venous thromboembolism. Anti-Factor Xa (anti-FXa) levels are used to monitor the anticoagulant effect of LMWHs and such assays are routinely employed in hospital diagnostic laboratories. In this study, a fluorogenic anti-FXa assay was developed using a commercially available fluorogenic substrate with an attached 6-amino-1naphthalene-sulfonamide (ANSN) fluorophore and was used for the determination of two LMWHs, enoxaparin and tinzaparin and the heparinoid, danaparoid. The assay was based on the complexation of heparinised plasma with $100 \mathrm{nM}$ exogenous $\mathrm{FXa}$ and $25 \mu \mathrm{M}$ of the fluorogenic substrate Mes-DLGR-ANSN $\left(\mathrm{C}_{2} \mathrm{H}_{5}\right)_{2}(\mathrm{SN}-7)$. The assay was tested with pooled plasma samples spiked with anticoagulant concentrations in the range $0-1.6 \mathrm{U} \mathrm{mL}^{-1}$. The statistically sensitive assay range was $0-0.4 \mathrm{U} \mathrm{mL}^{-1}$ for enoxaparin and tinzaparin and $0-0.2 \mathrm{U} \mathrm{mL}^{-1}$ for danaparoid, with assay variation typically below $10.5 \%$. This assay was then compared with a previously published fluorogenic anti-FXa assay developed with the peptide substrate, methylsulfonyl-t-cyclohexylalanyl-glycyl-arginine-7-amino-4-methylcoumarin acetate (Pefafluor FXa). Both assays were compared in terms of fluorescence intensity, lag times and sensitivity to anticoagulants.

44 Keywords FXa - Fluorogenic substrate - AMC - ANSN - Low molecular weight heparins separated by ' - ' Danaparoid

45 Foot note This paper was published in the special issue Heparin Characterization with information Guest Editor Cynthia K. Larive. 
 \\ Comparative study of Factor Xa fluorogenic substrates
} and their influence on the quantification of LMWHs

\author{
Vanessa Castro-López • Leanne F. Harris • \\ James S. O'Donnell • Anthony J. Killard
}

Received: 18 August 2010 /Revised: 6 October 2010 / Accepted: 7 October 2010

9 (C) Springer-Verlag 2010

\begin{abstract}
Low molecular weight heparins (LMWHs) are recognised as the preferred anticoagulants in the prevention and treatment of venous thromboembolism. Anti-Factor Xa (anti-FXa) levels are used to monitor the anticoagulant effect of LMWHs and such assays are routinely employed in hospital diagnostic laboratories. In this study, a fluorogenic anti-FXa assay was developed using a commercially available fluorogenic substrate with an attached 6-amino-1naphthalene-sulfonamide (ANSN) fluorophore and was used for the determination of two LMWHs, enoxaparin and tinzaparin and the heparinoid, danaparoid. The assay was based on the complexation of heparinised plasma with $100 \mathrm{nM}$ exogenous FXa and $25 \mu \mathrm{M}$ of the fluorogenic substrate Mes-D-LGR-ANSN $\left(\mathrm{C}_{2} \mathrm{H}_{5}\right)_{2}$ (SN-7). The assay was tested with pooled plasma samples spiked with anticoagulant concentrations in the range $0-1.6 \mathrm{U} \mathrm{mL}^{-1}$. The statistically sensitive assay range was $0-0.4 \mathrm{U} \mathrm{mL}^{-1}$ for enoxaparin and tinzaparin and $0-0.2 \mathrm{U} \mathrm{mL}^{-1}$ for danaparoid, with assay variation typically below $10.5 \%$. This assay was then compared with a previously published fluorogenic antiFXa assay developed with the peptide substrate, methylsulfonyl-D-cyclohexylalanyl-glycyl-arginine-7-amino-
\end{abstract}

This paper was published in the special issue Heparin Characterization with Guest Editor Cynthia K. Larive.

V. Castro-López · L. F. Harris · J. S. O’Donnell • A. J. Killard $(\bowtie)$ Biomedical Diagnostics Institute,

National Centre for Sensor Research, Dublin City University,

Dublin 9, Ireland

e-mail: tony.killard@dcu.ie

J. S. O’Donnell

Haemostasis Research Group, Trinity College Dublin,

National Centre for Hereditary Coagulation Disorders, St. James's Hospital,

Dublin 8, Ireland 4-methylcoumarin acetate (Pefafluor FXa). Both assays were compared in terms of fluorescence intensity, lag times and sensitivity to anticoagulants.

Keywords FXa · Fluorogenic substrate - AMC · ANSN . Low molecular weight heparins $\cdot$ Danaparoid

Introduction

Low molecular weight heparins (LMWHs) are efficacious anticoagulants administered for both the prophylaxis and treatment of venous and arterial thromboembolic disorders and acute coronary syndromes [1-3]. LMWHs require less laboratory monitoring than unfractionated heparin (UFH) as they exhibit a more predictable pharmacokinetic response with reduced bleeding risk [4]. However, clinical situations do arise where the anticoagulant effect of LMWHs is unpredictable. As a result, laboratory monitoring of LMWHs is necessary in special patient cohorts including pregnant women, the elderly, children, patients with renal insufficiency, and patients at the extremes of body weight $[2,5]$.

The recommended test for monitoring LMWHs therapy is the anti-Factor Xa (anti-FXa) assay due to the strong inhibition of FXa by LMWHs [5]. The first anti-FXa assay was a clotting time test based on the heparin-accelerated inhibition of FXa [6]. Anti-FXa assays currently employed in the central laboratory setting are chromogenic and use a synthetic FXa peptide substrate coupled to a cleavable chromophore [7] and [2]. The application of synthetic peptide substrates to the analysis of coagulation proteins confers many advantages over traditional clot-based assays, in terms of greater sensitivity, specificity, accuracy, and simplicity [8]. 
The endopeptidases involved in coagulation and fibrinolysis are trypsin-like serine endopeptidases [9]. Research into the use of synthetic substrates for the evaluation of coagulation endopeptidases began in the 1950s and 1960s. Initially, chromogenic substrates based on the chromophore $p$-nitroaniline were developed for thrombin, plasmin, and trypsin analysis $[8,10]$, followed by the development of assays using fluorogenic substrates for thrombin [11, 12]. Once the specific peptide cleavage sequence was known, these developments were rapidly extended to other coagulation proteins in the $70 \mathrm{~s}$ and $80 \mathrm{~s}$, resulting in a new strategy for the biochemical study of the coagulation system [10].

Factor Xa occupies a critical position in the coagulation cascade; hence its joint popularity with thrombin as a therapeutic target for anticoagulant therapy. The first photometric anti-FXa assay was introduced in 1976 [13] followed by the rapid development of more specific chromogenic substrates and eventually a fluorogenic substrate specific for FXa which was introduced in 1977 [14]. Both chromogenic and fluorogenic assays are well suited to the measurement of heparin, as there is a direct relationship between the functional activity of heparin and its effect on antithrombin allowing for greater precision in its determination [8]. Fluorescence-based measurements offer further advantages over colorimetric assays, such as superior sensitivity and specificity $[14,15]$, as well as measurement in a broader range of sample types such as platelet poor plasma, platelet rich plasma, and whole blood $[16,13]$.

Two fluorophores are principally used in commercial substrates for the analysis of coagulation proteins, namely 7-amino-4-methylcoumarin (AMC) and 6-amino1-naphthalene-sulfonamide (ANSN) [17, 18, 19, 20]. The majority of studies have focussed on the reactivity of substrates containing 7-amino-4-methylcoumarin, as it is the most common fluorogenic leaving group used in bioassays [21]. Coumarins can be described as a broad class of fluorophores resulting in UV or near-UV excitation wavelengths with a high quantum yield and low extinction coefficient [22]. The naphthalenesulfonamides were reported in 1992 as a new fluorescent group for substrates of amidases which are also excited in the UV range. Their high quantum yield and the presence of a sulfonyl moiety allows for a range of chemical modifications which can enhance enzymatic substrate specificity [9]. However, given the availability of these substrates, few publications have evaluated their usefulness in the development of anti-FXa assays.

A novel fluorogenic anti-FXa assay was developed in this study using a peptide substrate for FXa with an attached ANSN fluorophore and was compared to a previously developed assay based on an AMC fluorescent leaving group [16]. A comparison of assay responses to pharmacological concentrations of LMWHs and danaparoid in commercial pooled plasma is reported.

\section{Materials and methods}

Reagents

Water (ACS reagent) and HEPES (minimum 99.5\% titration) were purchased from Sigma-Aldrich (Dublin, Ireland). Filtered HEPES was prepared at a concentration of $10 \mathrm{mM}$ (pH 7.4). A $100 \mathrm{mM}$ filtered stock solution of $\mathrm{CaCl}_{2}$ from Fluka BioChemika (Buchs, Switzerland) was prepared from a $1 \mathrm{M} \mathrm{CaCl}_{2}$ solution. The fluorogenic substrate methylsulfonyl-D-cyclohexylalanyl-glycyl-arginine7-amino-4-methylcoumarin acetate (Pefafluor FXa) was purchased from Pentapharm (Basel, Switzerland). It was reconstituted in $1 \mathrm{~mL}$ of water having a final concentration of $10 \mathrm{mM}$, aliquoted and stored at $-20{ }^{\circ} \mathrm{C}$. Dilutions from $10 \mathrm{mM}$ stock solutions down to $10 \mu \mathrm{M}$ were freshly prepared with water when needed. Subsequent dilutions were prepared in $10 \mathrm{mM}$ HEPES. Tubes were covered with aluminium foil to protect from exposure to light. The fluorogenic substrate Mes-D-LGR-ANSN $\left(\mathrm{C}_{2} \mathrm{H}_{5}\right)_{2}$ (SN-7), containing the fluorescent reporter group ANSN, was acquired from Haematologic Technologies Inc. (Vermont, USA). Stock solutions of $10 \mathrm{mM}$ in DMSO were stored at $-20{ }^{\circ} \mathrm{C}$ and also protected from light with aluminium foil. Dilutions of stock solutions were performed with $10 \mathrm{mM}$ HEPES. Table 1 summarises the kinetic constants and physico-chemical properties of both the Pefafluor FXa and SN-7 fluorogenic substrates. These parameters were obtained from the suppliers. Kinetic constants refer to the cleavage of both fluorogenic substrates by the endopeptidase FXa. Purified human FXa (serine endopeptidase; code number: EC 3.4.21.6) was obtained from HYPHEN BioMed (Neuville-Sur-Oise, France). Tinzaparin $\left(\right.$ Innohep $\left.{ }^{\circledR}\right)$ was obtained from LEO Pharma (Ballerup, Denmark). Enoxaparin $\left(\right.$ Clexane $\left.^{\circledR}\right)$ and danaparoid (Orgaran ${ }^{\circledR}$ ) were from Sanofi-Aventis (Paris, France) and Schering-Plough (New Jersey, USA), respectively. Human pooled plasma was purchased from Helena Biosciences Europe (Tyne and Wear, UK). Lyophilised plasma was reconstituted in $1 \mathrm{~mL}$ of water and left to stabilise for at least $20 \mathrm{~min}$ at room temperature prior to use.

Apparatus and software

Fluorescence intensities were measured on an Infinite M200 microplate reader from Tecan Group Ltd. (Männedorf, Switzerland) equipped with a UV Xenon flashlamp. 160 Flat, black-bottom 96-well polystyrol FluorNunc ${ }^{\mathrm{TM}}$ micro- 
Comparative study of Factor Xa fluorogenic substrates

Table 1 Kinetic constants and physico-chemical properties of both fluorogenic substrates

\begin{tabular}{|c|c|c|}
\hline Fluorogenic substrate & SN-7 & Pefafluor FXa \\
\hline Formula & Mes-D-LGR-ANSN $\left(\mathrm{C}_{2} \mathrm{H}_{5}\right)_{2}$ & $\begin{array}{c}\mathrm{CH}_{3} \mathrm{SO}_{2} \text {-D-CHA-Gly-Arg- } \\
\text { AMC.AcOH }\end{array}$ \\
\hline Physical form & Liquid & Lyophilised powder \\
\hline Fluorophore chemical structure & $\mathrm{SO}_{2} \mathrm{~N}\left(\mathrm{C}_{2}\right.$ & \\
\hline $\mathrm{M}_{\mathrm{w}}\left(\mathrm{g} \mathrm{mol}^{-1}\right)$ & 682.8 & 8 \\
\hline$K_{\mathbf{m}}(\mu \mathrm{M})$ & 125 & 220 \\
\hline$k_{\text {cat }}\left(\mathrm{s}^{-1}\right)$ & 36 & 162 \\
\hline$k_{\text {cat }} / K_{\mathrm{m}}\left(\mathrm{M}^{-1} \mathrm{~s}^{-1}\right)$ & 290,000 & $\sim 740,000$ \\
\hline Wavelength maxima (nm) & $352\left(\lambda_{\mathrm{ex}}\right), 470\left(\lambda_{\mathrm{em}}\right)$ & $342\left(\lambda_{\mathrm{ex}}\right), 440\left(\lambda_{\mathrm{em}}\right)$ \\
\hline
\end{tabular}

plates from Thermo Fisher Scientific (Roskilde, Denmark) were used.

\section{Fluorogenic anti-FXa assay}

Measurements were carried out in reconstituted citrated human pooled plasma. FXa and the ANSN-based fluorogenic substrate were titrated within the range of 0.1$100 \mathrm{nM}$ and $8.3-33.3 \mu \mathrm{M}\left(K_{\mathrm{m}}=125 \mu \mathrm{M}\right)$, respectively. Samples consisting of $6.25 \mu \mathrm{L}$ of $100 \mathrm{mM} \mathrm{CaCl}_{2}, 43.75 \mu \mathrm{L}$ of pooled plasma, and $50 \mu \mathrm{L}$ of FXa $(0.1-100 \mathrm{nM})$ were incubated at $37^{\circ} \mathrm{C}$ for $3 \mathrm{~min}$ and shaken for the first $150 \mathrm{~s}$. The reaction was started by adding $50 \mu \mathrm{L}$ of ANSN-based fluorogenic substrate $(8.3-33.3 \mu \mathrm{M})$. Samples within wells were mixed with the aid of orbital shaking at $37{ }^{\circ} \mathrm{C}$ for 30 s. Finally, immediately after shaking, fluorescence measurements were recorded at $37{ }^{\circ} \mathrm{C}$ for $60 \mathrm{~min}$ with integration time of $20 \mu \mathrm{s}$. Fluorescence excitation was at $352 \mathrm{~nm}$ and emission was monitored at $470 \mathrm{~nm}$, corresponding to the excitation/emission wavelengths of the ANSN fluorophore. All measurements were carried out in triplicate. Following optimization of assay conditions, pooled commercial plasma samples were spiked with pharmacologically relevant concentrations $\left(0-1.6 \mathrm{U} \mathrm{mL}^{-1}\right)$ of therapeutic anticoagulants including enoxaparin, tinzaparin, and danaparoid. The reaction rate (slope), which is defined as the change in fluorescence divided by the change in time (i.e., $\mathrm{d} F / \mathrm{d} t$ ), was measured as the linear portion of the fluorescence response profile and plotted versus anticoagulant concentration. The assay using the Pefafluor FXa fluorogenic substrate was optimised as previously described by Harris et al. [16]. The fluorescence excitation and emission wavelengths were $342 \mathrm{~nm}$ and $440 \mathrm{~nm}$, respectively, corresponding to the excitation/emission wavelengths of the AMC fluorophore. The only difference between these assays was the insertion of an incubation step in the ANSN-based assay to improve reproducibility.

Statistical analysis

All graphs were plotted using SigmaPlot 8.0. and SPSS 17.0 was used for statistical analysis. Intra-assay differences within the anticoagulant concentration range were compared using one-way analysis of variance (ANOVA), with subsequent post-hoc analysis performed (Scheffe's test) if significance was observed. A result of $p<0.05$ was considered statistically significant. Inter-assay differences between the two fluorogenic substrates employed were statistically analysed using the paired Student's $t$ test at a significance level of $5 \%$.

\section{Results}

Assay optimisation

In this study, two fluorogenic substrates with two different fluorophore leaving groups were compared using the antiFXa assay principle, whereby exogenous FXa added to heparinised plasma was inhibited by the heparin-AT complex and the resulting FXa activity was measured using fluorescence. A new assay is reported that measures the rate 
of ANSN fluorophore release as a result of FXa substrate cleavage and is compared to the rate of AMC fluorophore release which has been published previously [16]. Optimised assay concentrations for this new fluorogenic assay were determined by performing titrations of FXa from 0.1 to $100 \mathrm{nM}$ and fluorogenic substrate concentrations from 8.3 to $33.3 \mu \mathrm{M}$. To allow for differentiation in the assay reaction rates, the concentration range of the ANSN-based substrate was selected so that it was lower than the $K_{\mathrm{m}}$ value. The final working assay concentrations of $25 \mu \mathrm{M}$ ANSN-based fluorogenic substrate and $100 \mathrm{nM}$ FXa, conform to the optimisation criteria which included short lag times, fast reaction rates, and a broad fluorescence dynamic range for the differentiation of anticoagulant concentrations. The same criteria were also selected for the optimization of the AMC-based fluorogenic anti-FXa assay.

Evaluation of the ANSN-based anti-FXa fluorogenic assay

Three anticoagulant drugs were tested using the fluorogenic anti-FXa assay with the ANSN-based substrate in commercial pooled plasma.

The fluorescence intensity profiles over time for tinzaparin plasma samples in the fluorogenic anti-FXa assay can be seen in Fig. 1 and the inset shows the dose-response profile versus anticoagulant concentration. As the concentration of tinzaparin increased, the fluorescence profiles reached lower fluorescence intensity values after $1 \mathrm{~h}$. In the absence of tinzaparin, the maximum intensity value was $56,000 \mathrm{AU}$; with $0.2 \mathrm{U} \mathrm{mL}^{-1}$ the profile reached $40,000 \mathrm{AU}$ and 27,000 $\mathrm{AU}$ for $0.4 \mathrm{U} \mathrm{mL}^{-1}$. From 0.4 to $1.6 \mathrm{U} \mathrm{mL}^{-1}$, the maximum fluorescence intensity value was between 22,000 and 27,000 AU.
Lag times were calculated by extrapolation of the linear portion of the progression curve to its intersection with the $\mathrm{x}$-axis [23]. In the presence of higher anticoagulant concentrations, longer lag time values were observed. At low concentrations of 0 and $0.2 \mathrm{U} \mathrm{mL}^{-1}$ tinzaparin, the reaction was very quick and no lag time was observed. Lag times increased to 310 and $630 \mathrm{~s}$ for $0.4 \mathrm{U} \mathrm{mL}^{-1}$ and $0.6 \mathrm{U} \mathrm{mL}^{-1}$ respectively. At concentrations of $0.8-1.6 \mathrm{U} \mathrm{mL}^{-1}$ lag time values were $1,010 \mathrm{~s}$.

The reaction rates of the fluorescence profiles were calculated to generate dose-response profiles and a similar trend was observed for all drugs analysed, in that as anticoagulant concentration increased, the rate of the reaction decreased. The slope values were statistically different up to $0.4 \mathrm{U} \mathrm{mL}^{-1}(p<0.003)$ with significantly reduced sensitivity in the upper tinzaparin range (0.6$1.6 \mathrm{U} \mathrm{mL}^{-1}$ ).

The anti-FXa assay was also tested with enoxaparin, another member of the low molecular weight heparin family. The fluorescence profiles are very similar to those of tinzaparin (Fig. 2). The fluorescence profiles for $0 \mathrm{U} \mathrm{mL}^{-1}$ reached $52,000 \mathrm{AU}$ after $1 \mathrm{~h}$, for $0.2 \mathrm{U} \mathrm{mL}^{-1}$ the intensity value was $38,000 \mathrm{AU}$ and with $0.4 \mathrm{U} \mathrm{mL}^{-1}$ the profile reached 28,000 AU. At higher enoxaparin concentrations, the profiles reached maximum intensity values of 21,000 and 28,000 AU.

At low concentrations of enoxaparin lag times were absent but were calculated as $110 \mathrm{~s}$ for 0.4 and $0.6 \mathrm{U} \mathrm{mL}^{-1}$ enoxaparin. At higher concentrations, lag times increased to $590 \mathrm{~s}$ for 0.8 and $1 \mathrm{U} \mathrm{mL}^{-1}, 730 \mathrm{~s}$ for $1.2 \mathrm{U} \mathrm{mL}^{-1}$, and $910 \mathrm{~s}$ for 1.4 and $1.6 \mathrm{U} \mathrm{mL}^{-1}$.

The dose-response curve calculated from the linear slopes of the fluorescence profiles of enoxaparin can be
Fig. 1 Fluorescence intensity vs. time for the anti-FXa activity with tinzaparin $(n=3)$. Tinzaparin concentration increases from top to bottom. Inset Doseresponse calibration curve of tinzaparin in pooled plasma in the ANSN-based fluorogenic anti-FXa assay $(n=3)$, calculated from the linear slopes $(\mathrm{d} F / \mathrm{d} t)$ of the fluorescence response curves

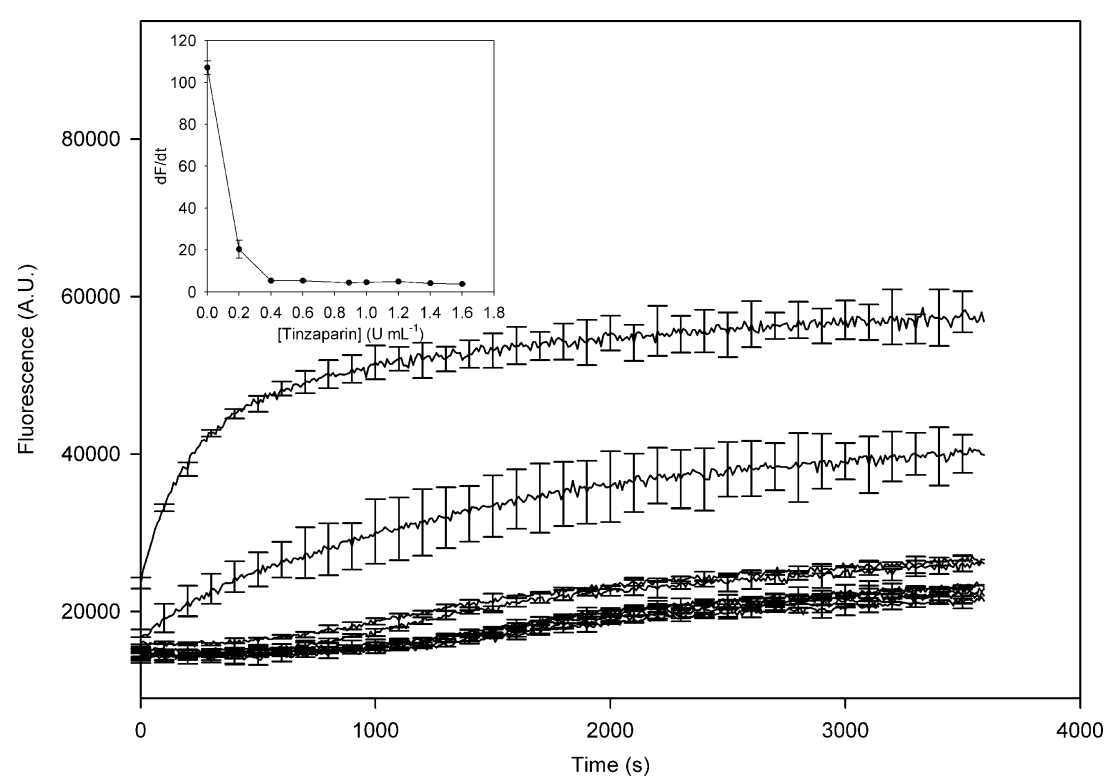


Comparative study of Factor Xa fluorogenic substrates

Fig. 2 Fluorescence intensity vs. time for the anti-FXa activity with enoxaparin $(n=3)$. Enoxaparin concentration increases from top to bottom. Inset Doseresponse calibration curve of enoxaparin in pooled plasma in the ANSN-based fluorogenic anti-FXa assay $(n=3)$, calculated from the linear slopes $(\mathrm{d} F / \mathrm{d} t)$ of the fluorescence response curves

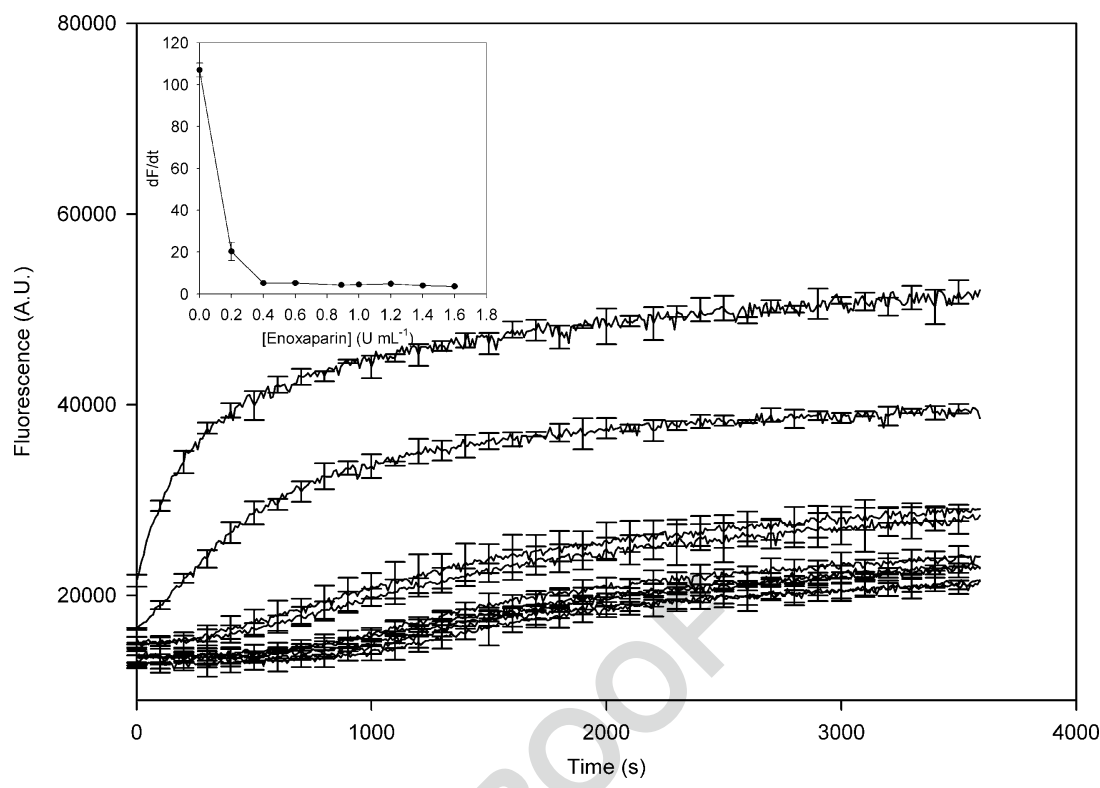

seen in Fig. 2 and good sensitivity was achieved with concentrations up to $0.4 \mathrm{U} \mathrm{mL}^{-1}(p<0.003)$.

Figure 3 shows the fluorescence profiles of the anti-Xa assay in the presence of danaparoid. The fluorescence profile for $0 \mathrm{U} \mathrm{mL}^{-1}$ reached 55,000 AU after $1 \mathrm{~h}$, at $0.2 \mathrm{U} \mathrm{mL}^{-1}$ the maximum fluorescence intensity value was $35,000 \mathrm{AU}$ and from 0.4 to $1.6 \mathrm{U} \mathrm{mL}^{-1}$ danaparoid, profiles reached fluorescence intensities between 22,000 and 29,000 AU.

Similar to the LMWHs, lag times were not observed at low concentrations of danaparoid. Lag times increased from $200 \mathrm{~s}$ at $0.4 \mathrm{U} \mathrm{mL}^{-1}$ to $780 \mathrm{~s}$ at $0.6 \mathrm{U} \mathrm{mL}^{-1}, 1,050 \mathrm{~s}$ at $0.8 \mathrm{U} \mathrm{mL}^{-1}$ and $1180 \mathrm{~s}$ at $1 \mathrm{U} \mathrm{mL}^{-1}$. At $1.2 \mathrm{U} \mathrm{mL}^{-1}$ and 1.6 $\mathrm{U} \mathrm{mL}^{-1}$ danaparoid lag times were $1,320 \mathrm{~s}$ and at $1.4 \mathrm{U} \mathrm{mL}^{-1}$ the lag time was calculated as $1,480 \mathrm{~s}$.
Inset of Fig. 3 shows the dose-response calibration curve of danaparoid in the fluorogenic anti-FXa assay. Statistical analysis returned significant differences in the variances with the Levene's test $(p=0.011)$, so one-way ANOVA could not be applied. When equal variances were not assumed, the Tamhane test returned significant differences between 0 and $0.2 \mathrm{U} \mathrm{mL}^{-1}$ danaparoid $(p=0.031)$.

The reaction rates were compared for all drugs tested using the normalised data (ratios of the dose-responses against the averaged dose-response value at $0 \mathrm{U} \mathrm{mL}^{-1}$ ). The reaction rates for enoxaparin were higher than tinzaparin rates at all concentrations from 0 to $1.6 \mathrm{U} \mathrm{mL}^{-1}$. Both low molecular weight heparins returned higher reaction rates than danaparoid in the statistically sensitive range of 0 $0.2 \mathrm{U} \mathrm{mL}^{-1}$. Enoxaparin reaction rates were the highest of
Fig. 3 Fluorescence intensity vs. time for the anti-FXa activity with danaparoid $(n=3)$. Danaparoid concentration increases from top to bottom. Inset Doseresponse calibration curve of danaparoid in pooled plasma in the ANSN-based fluorogenic anti-FXa assay $(n=3)$, calculated from the linear slopes $(\mathrm{d} F / \mathrm{d} t)$ of the fluorescence response curves

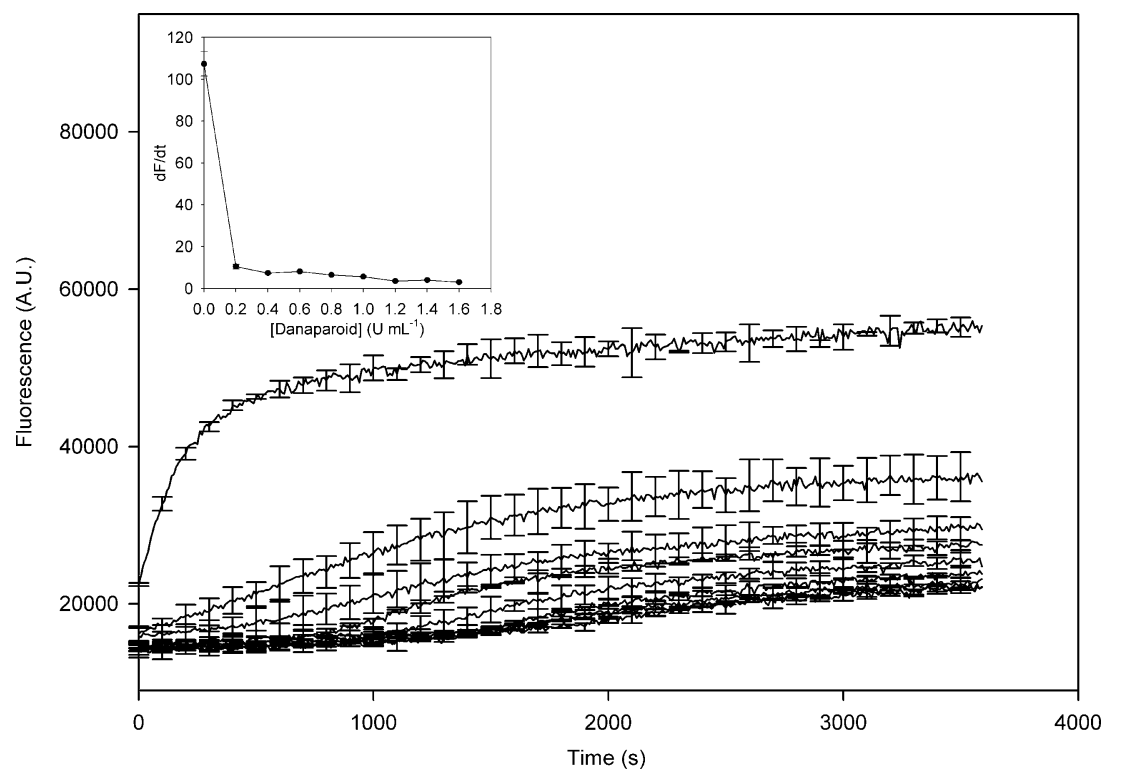


314 all drugs tested and only at concentrations of $0.6,0.8$, and $3151 \mathrm{U} \mathrm{mL}^{-1}$, were tinzaparin reaction rates lower than 316 danaparoid, but these fall into the statistically insensitive 317 range.

318 The analytical errors (standard deviation and percentage 319 coefficient of variation) related to each of the slope 320 measurements for all three anticoagulants were calculated. 321 All CV values were $<10.5 \%$ with the exception of $3220.2 \mathrm{U} \mathrm{mL}^{-1}$ tinzaparin which returned a $\mathrm{CV}$ value of $21 \%$.

Comparative studies of AMC versus ANSN-based fluorogenic assays

The two synthetic peptide substrates containing two different fluorogenic leaving groups were compared in terms of their fluorescence intensity, lag times, and slope values.

\section{Fluorescence intensity}

All three of the AMC-based fluorogenic assay reaction progress curves for enoxaparin, tinzaparin, and danaparoid, reported by Harris et al. [16], approached a similar maximum plateau value of product formation at approximately the same level (i.e., 48,000-53,000 AU) independent of anticoagulant type and concentration. This is an indication of substrate depletion and also that the enzyme remains stable under the conditions tested. In the ANSNbased study, the maximum value of product formed for all three anticoagulant drugs reached different fluorescence intensity values depending on anticoagulant concentration. As the concentration of anticoagulant increased from 0 to 1.6 $\mathrm{U} \mathrm{mL}^{-1}$, the fluorescence intensity values decreased from 56,000 to 22,000 for tinzaparin, 52,000 to 21,000 for enoxaparin and finally, from 55,000 to 22,000 for danaparoid.

\section{Lag time values}

The increase in lag time with increasing anticoagulant concentration was common to both fluorogenic assays as shown in Table 2. Furthermore, the ANSN-based anti-FXa fluorogenic assay returned smaller lag time values than the AMC-based assay for all anticoagulant concentrations.

\section{Slope values}

Analysis of slope values at $0 \mathrm{U} \mathrm{mL}^{-1}$ returned $25 \%$ variation in all assays. As a result, all slope values were normalised with respect to those at $0 \mathrm{U} \mathrm{mL}^{-1}$ for each anticoagulant. As can be seen in Fig. 4, the fluorogenic anti-FXa assay using the AMC fluorogenic substrate returned higher slopes than the ANSN fluorogenic assay in all instances. The inter-assay variability between the two fluorogenic substrates for each anticoagulant drug was statistically evaluated using the paired Student's $t$ test. Results indicate that there is a significant mean difference $(p<0.05)$ between the two fluorogenic anti-FXa assays for each anticoagulant at all concentrations, except for $0 \mathrm{U} \mathrm{mL}^{-1}$ as it corresponds to the unit value of normalisation in all cases.

Assay sensitivity

The intra-assay variability between different concentrations of anticoagulants was assessed for both fluorogenic substrates. Table 3 outlines the statistically sensitive range for both fluorogenic anti-FXa assays each containing a different leaving group in the presence of tinzaparin, enoxaparin, and danaparoid. When the ANSN-based fluorogenic anti-FXa assay was performed in the presence of tinzaparin, the slopes of the enzymatic reaction were statistically different up to $0.4 \mathrm{U} \mathrm{mL}^{-1}(p<0.05)$ at intervals of $0.2 \mathrm{U} \mathrm{mL}^{-1}$. In the case of the Pefafluor FXa substrate the assay proved to be sensitive up to $0.6 \mathrm{U} \mathrm{mL}-1$ tinzaparin $(p<0.001)$. This reduction in assay sensitivity for the ANSN-based fluorogenic anti-FXa assay was also observed for enoxaparin. The fluorogenic anti-FXa assay using the ANSN-based substrate resulted in a narrower statistically sensitive range from 0 to $0.4 \mathrm{U} \mathrm{mL}^{-1}(p<0.05)$ when compared with the AMC-based substrate assay range of $0-0.8 \mathrm{U} \mathrm{mL}^{-1}(p<0.001)$ for enoxaparin. The effect of danaparoid was also evaluated in both fluorogenic assays and a larger difference in assay sensitivity was observed. Response slopes to danaparoid concentrations at $0.2 \mathrm{U} \mathrm{mL}^{-1}$ intervals were statistically different up to $0.2 \mathrm{U} \mathrm{mL}^{-1}$ and $1 \mathrm{U} \mathrm{mL}^{-1}$ for the ANSN and AMC-based substrate assays, respectively. In all cases, the AMC-based substrate seems to offer a wider assay sensitive range compared with the ANSN-based fluorogenic substrate when quantifying both LMWHs and danaparoid.

Reproducibility (\%CV values)

Reproducibility of the two developed assays was determined using the percentage coefficient of variation $(\% \mathrm{CV})$. Comparing $\mathrm{CV}$ values between the two fluorogenic assays, results in lower variation for both low molecular weight heparins and danaparoid with the AMC fluorophore. Studies of precision for the fluorogenic anti-FXa assay using the AMC-based substrate showed a coefficient of variation ranging between $0.5 \%$ and $7 \%$ [16]. In the case of the ANSN-based assay, CV values were below $10.5 \%$ except for $0.2 \mathrm{U} \mathrm{mL}^{-1}$ tinzaparin which returned a $\mathrm{CV}$ of $21 \%$.
368 
Comparative study of Factor Xa fluorogenic substrates

Table 2 Lag times of averaged progress curves for both anti-FXa fluorogenic assays in the presence and absence of tinzaparin, enoxaparin, and danaparoid

\begin{tabular}{|c|c|c|c|c|c|c|}
\hline \multirow[t]{2}{*}{ Conc $\left(\mathrm{U} \mathrm{mL}^{-1}\right)$} & \multicolumn{2}{|c|}{ Enoxaparin $^{\mathrm{a}}$ (s) } & \multicolumn{2}{|c|}{$\operatorname{Tinzaparin}^{\mathrm{a}}$ (s) } & \multicolumn{2}{|c|}{ Danaparoid $^{\mathrm{a}}(\mathrm{s})$} \\
\hline & $\mathrm{AMC}$ & ANSN & $\mathrm{AMC}$ & ANSN & $\mathrm{AMC}$ & ANSN \\
\hline 0 & 200 & 0 & 160 & 0 & 220 & 0 \\
\hline 0.2 & 280 & 0 & 240 & 0 & 560 & 0 \\
\hline 0.4 & 420 & 110 & 380 & 310 & 800 & 200 \\
\hline 0.6 & 580 & 110 & 670 & 630 & 1,420 & 780 \\
\hline 0.8 & 850 & 590 & 900 & 1,010 & 2,010 & 1,050 \\
\hline 1 & 940 & 590 & 1,040 & 1,010 & 2,070 & 1,180 \\
\hline 1.2 & 1,020 & 730 & 1,440 & 1,010 & 2,440 & 1,320 \\
\hline 1.4 & 1,260 & 910 & 1,800 & 1,010 & $>3,600$ & 1,480 \\
\hline 1.6 & 1,310 & 910 & 2,000 & 1,010 & $>3,600$ & 1,320 \\
\hline
\end{tabular}

desirable properties, such as the photo and chemical stability of the generated fluorescent group, the Stokes shift, the solubility of substrate and fluorescent product in aqueous buffer, and the fluorescence quantum yield, to mention just a few [9]. To date, several synthetic fluorogenic substrates targeting FXa have been developed with different peptidic groups, attached to just two fluorescent detecting groups namely ANSN [9] and AMC [14].

This paper sought to develop a new fluorogenic anti-FXa assay using the commercially available ANSN-based fluorogenic substrate for $\mathrm{FXa}$ and compare it with the AMCbased fluorogenic anti-FXa assay previously investigated by Harris et al. [16] in the presence and absence of two LMWHs (i.e., enoxaparin and tinzaparin) and danaparoid.

The principle of the assay is to measure the rate of fluorescent tag release which results from FXa proteolysis of the two synthetic peptide substrates, in the presence and absence of three anticoagulants. From the results obtained, different observations can be made: firstly, the anti-FXa $\mathrm{t} 2.2$
Fig. 4 Dose-response curves (normalised data) of the fluorogenic: ANSN-based anti-FXa assay to tinzaparin (empty circle), enoxaparin (empty upright triangle), and danaparoid (empty square); AMC-based anti-FXa assay to tinzaparin (filled circle), enoxaparin (filled upright triangle), and danaparoid (filled square)

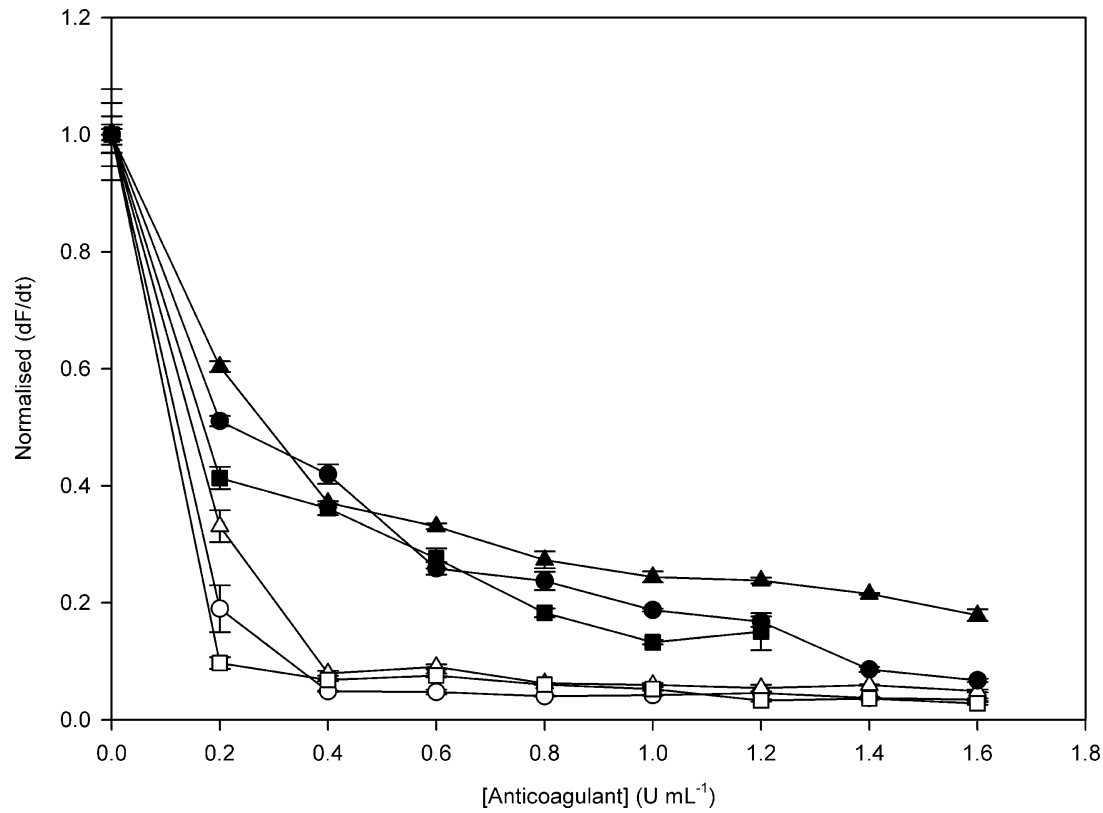


t3.1 Table 3 Comparison of the statistically sensitive range for each anticoagulant tested in two fluorogenic anti-FXa assays based on different fluorophore leaving groups

t3.2 Anticoagulant drug

t3.3

$\mathrm{t} 3.4$

t3.5

$\mathrm{t} 3.6$ rapidly.
Statistically sensitive range $\left(\mathrm{U} \mathrm{mL}^{-1}\right)$

\begin{tabular}{lcc}
\cline { 2 - 3 } & \multicolumn{2}{l}{ ANSN } \\
\hline Tinzaparin & $0-0.4$ & $0-0.6$ \\
Enoxaparin & $0-0.4$ & $0-0.8$ \\
Danaparoid & $0-0.2$ & $0-1$ \\
\hline
\end{tabular}

assay presented in this paper was statistically differentiated at intervals of 0.2 up to $0.4 \mathrm{U} \mathrm{mL}^{-1}$ for enoxaparin and tinzaparin. It was also found to be statistically sensitive for danaparoid up to $0.2 \mathrm{U} \mathrm{mL}^{-1}$. $\mathrm{CV}$ values were $<10.5 \%$ for all anticoagulant drugs except for tinzaparin at $0.2 \mathrm{U} \mathrm{mL}^{-1}$, which returned $21 \%$. The sensitivity and dynamic range of the fluorogenic anti-FXa assay developed in this study are smaller than the values shown by the commercially available chromogenic anti-FXa assays. Most of the chromogenic anti-FXa assays are able to measure concentrations of LMWHs up to $1 \mathrm{U} / \mathrm{ml}$ with $\% \mathrm{CV}$ values between 5\% and 10\% [16].

Secondly, the reaction progress curves of the ANSNbased assay show a very different time-course of product formation compared with those of the AMC-based assay. In this study, we observed a decrease in fluorophore formation with increasing anticoagulant concentration. In other words, the reaction progress curves reach lower fluorescence intensities as the concentration of anticoagulant increases. This could be indicative of inhibition by the accumulating products, instability of the enzyme or some other component of the assay system, the presence of enzyme-activated irreversible inhibitors [25], i.e., antithrombin (ATIII) in human plasma or the anticoagulants added to the assay. In comparison, the AMC-based fluorogenic assay showed similar maximum plateau values at all concentrations of FXa inhibitors, indicating enzyme stability and fluorogenic substrate depletion. Moreover, the ANSN substrate did not yield as good a signal-to-noise ratio as the AMC-based substrate; however, the former was not consumed as

Thirdly, lag time values for the ANSN-based assay were shorter compared with the AMC-based assay for all anticoagulants and at all concentrations. Considering that the $K_{\mathrm{m}}$ value for ANSN is 125 and $220 \mu \mathrm{M}$ for AMC, it is expected that the ANSN substrate would have greater binding affinity for FXa (i.e., shorter lag times) than the AMC substrate. It has been suggested by Butenas et al. [9] that this is due to the limited possibility for modification of the AMC group. The lack of an adequate functional group does not allow for optimisation of substrate interaction compared to the presence of a modifiable sulfonyl moiety in the ANSN group which can enhance substrate specificity. Additionally, lag times were found to increase with increasing anticoagulant concentration. This shows the ability of FXa inhibitors to form a complex with ATIII and FXa. Any FXa not neutralised is free to react with the fluorogenic substrates; therefore lag times can be due to the time taken for the concentrations of the intermediate enzyme-substrate and enzyme-product complexes to rise to their steady-state levels [25].

And finally, the rates of the enzymatic reaction (i.e., rate of fluorophore formation) were higher for the AMC-based fluorogenic anti-FXa assay in all cases. In the presence of enoxaparin the AMC-based fluorogenic assay resulted in reaction rates that were between 3.6- and 4.8-fold higher than the ANSN assay except for $0.2 \mathrm{U} \mathrm{mL}^{-1}$ which was 1.8-fold higher. Tinzaparin reaction rates were between 2.3and 8.4-fold higher than ANSN rates, and finally, danaparoid resulted in rates of reaction that were 2.6- to 5.1-fold higher than those in the ANSN assay. This behaviour is related to the catalytic constant $\left(k_{\text {cat }}\right)$ values of FXa with respect to the two synthetic peptide substrates. The $k_{\text {cat }}$ value for the ANSN substrate is 36 and $162 \mathrm{~s}^{-1}$ for the AMC substrate. Thus, the higher the $k_{\text {cat }}$ value, the faster the enzyme-substrate complex conversion to fluorophore. Hence, these values indicate that FXa should convert the AMC-based fluorogenic substrate into its fluorophore 4.5fold quicker than the ANSN-based fluorogenic substrate. This explanation is consistent with our findings.

In terms of assay sensitivity and reproducibility, the AMC-based substrate offers a wider assay sensitive range for enoxaparin, tinzaparin, and danaparoid compared with the ANSN detecting group in the fluorogenic anti-FXa assay. The ANSN-based (AMC-based) assay resulted in detection ranges of $0-0.4 \mathrm{U} \mathrm{mL}^{-1}\left(0-0.8 \mathrm{U} \mathrm{mL}^{-1}\right)$ for enoxaparin, $0-0.4 \mathrm{U} \mathrm{mL}^{-1}\left(0-0.6 \mathrm{U} \mathrm{mL}^{-1}\right)$ for tinzaparin, and $0-0.2 \mathrm{U} \mathrm{mL}^{-1}\left(0-1 \mathrm{U} \mathrm{mL}^{-1}\right)$ for danaparoid. In addition, assay reproducibility for both LMWHs and danaparoid when using the ANSN-based substrate was $<10.5 \%$, while the AMC-based substrate returned CVs of $<7 \%$.

Assay sensitivity as well as assay precision can also be analysed in terms of the $k_{\text {cat }} / K_{\mathrm{m}}$ ("specificity constant") values of FXa with respect to the two fluorogenic substrates. FXa has a $k_{\text {cat }} / K_{\mathrm{m}}$ of $290,000 \mathrm{M}^{-1} \mathrm{~s}^{-1}$ for the ANSN fluorogenic substrate and $\sim 740,000 \mathrm{M}^{-1} \mathrm{~s}^{-1}$ for the AMC substrate. The importance of $k_{\text {cat }} / K_{\mathrm{m}}$ is that it determines the specificity of an enzyme for competing substrates. Therefore taking into account these two values, FXa shows a 2.5-fold greater specificity for AMC than for ANSN which translates into a wider assay sensitive range and better assay reproducibility. Therefore, what appears to be a poor substrate in terms of affinity for FXa (i.e. Pefafluor FXa has a relatively high $K_{\mathrm{m}}$ of $220 \mu \mathrm{M}$ 
540 compared with $125 \mu \mathrm{M}$ for SN-7), it actually shows an 541 overall greater effectiveness for substrate hydrolysis. 542 However, it has been suggested by Bromfield et al. [18] 543 who performed competitive inhibition assays for FXa with 544 the fluorogenic coumarin substrate Boc-IEGR-AMC, that

substrates with low $K_{\mathrm{m}}$ values rather than high $k_{\text {cat }} / K_{\mathrm{m}}$ values may be better indicators of inhibitor potential for a peptidic sequence. Nevertheless, it is a complex area of research due to the open and flat architecture of the FXa active site $[26,27]$ which results in its low selectivity for peptide substrates [28].

Overall, fluorogenic substrates incorporating the AMC leaving group are commonly used probes in proteolytic assays [29], fluorogenic thrombin generation assays [30, $31,32,33,34]$ and more specifically in fluorogenic FXa assays [35, 36, 37, 38, 39]. The use of ANSN-based fluorogenic assays has also been described, but to a lesser extent for activated protein C [19], human factor VIIa and factor VIIa-tissue factor [40], and lately, for the Mytilus edulis anticoagulant peptide [41].

In summary, a new fluorogenic anti-FXa assay has been investigated in human pooled plasma based on the fluorescent reporter group ANSN. It was capable of statistically differentiating enoxaparin up to $0.4 \mathrm{U} \mathrm{mL}^{-1}$, tinzaparin up to $0.4 \mathrm{U} \mathrm{mL}^{-1}$, and danaparoid up to $0.2 \mathrm{U} \mathrm{mL}^{-1}$ with $\mathrm{CVs}$ of $<10.5 \%$. Moreover, it was compared with the 7-amino-4-methylcoumarin-based fluorogenic anti-FXa assay previously developed by Harris et al. [16]. Results indicate that the AMC-based fluorogenic anti-FXa assay is quicker, it has a wider sensitive range and it is more precise than the ANSN-based fluorogenic antiFXa assay examined in this study.

Acknowledgment This work was supported by Enterprise Ireland under Grant No. TD/2009/0124.

\section{References}

1. Melnikova I (2009) The anticoagulants market. Nat Rev Drug Discovery 8:353-354

2. Lim W (2010) Using low molecular weight heparin in special patient populations. J Thromb Thrombolysis 29:233-240

3. Wood B, Fitzpatrick L (2010) A review of the prevention and treatment of venous thromboembolism. Formulary 45:91-100

4. Hirsh J, Warkentin TE, Shaughnessy SG, Anand SS, Halperin JL, Raschke R, Granger C, Ohman EM, Dalen JE (2001) Heparin and low-molecular-weight heparin-mechanisms of action, pharmacokinetics, dosing, monitoring, efficacy, and safety. Chest 119:64S-94S

5. Baglin T, Barrowcliffe TW, Cohen A, Greaves M (2006) Guidelines on the use and monitoring of heparin. Br J Haematol 133:19-34

6. Yin ET, Wessler S, Butler JV (1973) Plasma heparin: a unique, practical, submicrogram-sensitive assay. J Lab Clin Med 81:298310

7. Bates SM, Weitz JI (2005) Coagulation assays. Circulation 112: e53-e60
8. Messmore HLJ, Fareed J, Kniffin J, Squillaci G, Walenga J (1981) Synthetic substrate assays of the coagulation enzymes and their inhibitors comparison with clotting and immunologic methods for clinical and experimental usage. Ann NY Acad Sci 370:785-797

9. Butenas S, Orfeo T, Lawson JH, Mann KG (1992) Aminonaphthalenesulfonamides, a new class of modifiable fluorescent detecting groups and their use in substrates for serine protease enzymes. Biochemistry 31:5399-5411

10. Fareed J, Messmore HL, Bermes EW (1980) New perspectives in coagulation testing. Clin Chem 26:1380-1391

11. Mitchell GA, Hudson PM, Huseby RM, Pochron SP, Gargiulo RJ (1978) Fluorescent substrate assay for antithrombin-III. Thromb Res 12:219-225

12. Bishop RC, Hudson PM, Mitchell GA, Pochron SP (1981) Use of fluorogenic substrates for the assay of antithrombin III and heparin. Ann NY Acad Sci 370:720-730

13. Teien AN, Lie M, Abildgaard U (1976) Assay of heparin in plasma using a chromogenic substrate for activated factor $\mathrm{X}$. Thromb Res 8:413-416

14. Morita T, Kato H, Iwanaga S, Takada K, Kimura T, Sakakibara S (1977) New fluorogenic substrates for $\alpha$-Thrombin, Factor Xa, Kallikreins, and Urokinase. J Biochem 82:1495-1498

15. Fareed J, Messmore HL, Walenga JM, Bermes EWJ (1983) Synthetic peptide substrates in hemostatic testing. Crit Rev Clin Lab Sci 19:71-134

16. Harris LF, Castro-López V, Hammadi N, O’Donnell JS, Killard AJ (2010) Development of a fluorescent anti-factor Xa assay to monitor unfractionated and low molecular weight heparins. Talanta 81:1725-1730

17. Board PG (1982) The use of fluorogenic peptide substrates for the detection of coagulation factors II and X after electrophoresis. Ann Hum Genet 46:293-298

18. Bromfield KM, Quinsey NS, Duggan PJ, Pike RN (2006) Approaches to selective peptidic inhibitors of factor Xa. Chem Biol Drug Des 68:11-19

19. Butenas S, Drungilaite V, Mann KG (1995) Fluorogenic substrates for activated protein $\mathrm{C}$ : substrate structure-efficiency correlation. Anal Biochem 225:231-241

20. Butenas S, van't Veer C, Mann KG (1997) Evaluation of the initiation phase of blood coagulation using ultrasensitive assays for serine proteases. J Biol Chem 272:21527-21533

21. Diamond SL (2007) Methods for mapping protease specificity. Curr Opin Chem Biol 11:46-51

22. Lavis LD, Raines RT (2008) Bright ideas for chemical biology. ACS Chem Biol 3:142-155

23. Kierstan KTE, Beezer AE, Mitchell JC, Hadgraft J, Raghavan SL, Davis AF (2001) UV-spectrophotometry study of membrane transport processes with a novel diffusion cell. Int $\mathrm{J}$ Pharm 229:87-94

24. Tripodi A, van den Besselaar A (2009) Laboratory monitoring of anticoagulation: where do we stand? Semin Thromb Hemost 35:34-41

25. Tipton KF (1992) In: Eisenthal R, Danson MJ (eds) Enzyme assays: a practical approach, 1st edn. Oxford University Press, Oxford

26. Brandstetter H, Kuhne A, Bode W, Huber R, von der Saal W, Wirthensohn K, Engh RA (1996) X-ray structure of active siteinhibited clotting factor $\mathrm{Xa}$-implications for drug design and substrate recognition. J Biol Chem 271:29988-29992

27. Padmanabhan K, Padmanabhan KP, Tulinsky A, Park CH, Bode W, Huber R, Blankenship DT, Cardin AD, Kisiel W (1993) Structure of human $\operatorname{des}(1-45)$ factor Xa at 2.2 A resolution. J Mol Biol 232:947-966

28. Bianchini EP, Louvain VB, Marque PE, Juliano MA, Juliano L, Le Bonniec BF (2002) Mapping of the catalytic groove
595

596

597

598

599

600

601

602

603

604

605

606

607

608

609

610

611

612

613

614

615

616

617

618

619

620

621

622

623

624

625

626

627

628

629

630

631

632

633

634

635

636

637

638

639

640

641

642

643

644

645

646

647

648

649

650

651

652

653

654

655

656

657

658

659

660 
preferences of factor Xa reveals an inadequate selectivity for its macromolecule substrates. J Biol Chem 277:20527-20534

29. Zimmerman M, Ashe B, Yurewicz EC, Patel G (1977) Sensitive assays for trypsin, elastase, and chymotrypsin using new fluorogenic substrates. Anal Biochem 78:47-51

30. Ramjee MK (2000) The use of fluorogenic substrates to monitor thrombin generation for the analysis of plasma and whole blood coagulation. Anal Biochem 277:11-18

31. Hemker HC, Giesen PLA, Ramjee M, Wagenvoord R, Beguin S (2000) The thrombogram: monitoring thrombin generation in platelet rich plasma. Thromb Haemost 83:589-591

32. Hemker HC, Giesen P, Al Dieri R, Regnault V, de Smedt E, Wagenvoord R, Lecompte T, Beguin S (2003) Calibrated automated thrombin generation measurement in clotting plasma. Pathophysiol Haemost Thromb 33:4-15

33. Gerotziafas GT, Petropoulou AD, Verdy E, Samama MM, Elalamy I (2007) Effect of the anti-factor Xa and anti-factor IIa activities of low-molecular-weight heparins upon the phases of thrombin generation. J Thromb Haemost 5:955-962

34. Adams M (2009) Assessment of thrombin generation: useful or hype? Semin Thromb Hemost 35:104-110

35. Kawabata SI, Miura T, Morita T, Kato H, Fujikawa K, Iwanaga S, Takada K, Kimura T, Sakakibara S (1988) Highly sensitive peptide-4-methylcoumaryl-7-amide substrates for blood-clotting proteases and trypsin. Eur J Biochem 172:17-25

36. Jordan SP, Mao SS, Lewis SD, Shafer JA (1992) Reaction pathway for inhibition of blood coagulation factor Xa by tick anticoagulant peptide. Biochemistry 31:5374-5380

37. Brecher AS, Koterba AP, Basista MH (1996) Coagulation protein function. IV. Effect of acetaldehyde upon factor X and factor Xa, the proteins at the gateway to the common coagulation pathway. Alcohol 13:539-545

38. Mao SS, Przysiecki CT, Krueger JA, Cooper CM, Lewis SD, Joyce J, Lellis C, Garsky VM, Sardana M, Shafer JA (1998) Selective inhibition of factor $\mathrm{Xa}$ in the prothrombinase complex by the carboxyl-terminal domain of antistasin. J Biol Chem 273:30086-30091

39. Lin PH, Sinha U, Betz A (2001) Antithrombin binding of low molecular weight heparins and inhibition of factor Xa. Biochim Biophys Acta 1526:105-113

40. Butenas S, Ribarik N, Mann KG (1993) Synthetic substrates for human factor VIIa and factor VIIa-tissue factor. Biochemistry 32:6531-6538

41. Jung W, Kim S (2009) Isolation and characterisation of an anticoagulant oligopeptide from blue mussel, Mytilus edulis. Food Chem 117:687-692 


\section{AUTHOR QUERY}

\section{AUTHOR PLEASE ANSWER QUERY.}

No Query. 